\title{
Shock Metamorphism of Silicate Glasses ${ }^{1}$
}

\author{
Rex V. Gibbons and Thomas J. Ahrens \\ Division of Geological and Planetary Sciences \\ California Institute of Technology, Seismological Laboratory \\ Pasadena, California 91109
}

\begin{abstract}
The changes in refractive index caused by shock compression have been determined for tektite, soda-lime, and silica glasses shocked to pressures up to $460 \mathrm{~kb}$. For shock compression below $80 \mathrm{~kb}$ for fused silica and $40 \mathrm{~kb}$ for tektite and soda-lime glasses, compression is reversible as the refractive indices are within 0.0025 of the starting values. Index increases of $0.01,0.04$, and 0.06 are observed for soda-lime, tektite, and silica glasses shocked to pressures of 80,130 , and $140 \mathrm{~kb}$ respectively. For soda-lime glass subjected to shock pressures between 80 and $230 \mathrm{~kb}$ there is a decrease in the postshock refractive index to $n=1.5211$ at $230 \mathrm{~kb}$. For fused silica shocked to pressures of 140 to $460 \mathrm{~kb}$, refractive index drops from 1.52 to 1.47. The reasons for these decreases in index are not obvious. New values for postshock temperatures for fused silica based on release adiabat data, e.g. $\sim 1000^{\circ} \mathrm{C}$ for a shock state at $250 \mathrm{~kb}$, suggest that the decreases in refractive index are caused by a combination of decompression along release adiabats and reconstructive transformation from a shockinduced stishovitelike phase to a low-density glass. Postshock densities calculated from the refractive index data agree closely with those calculated from the release adiabat data.
\end{abstract}

Shock recovery experiments to peak pressures of $460 \mathrm{~kb}$ have been carried out on three series of silicate glasses, namely, tektite, sodalime, and silica. Our goal in carrying out these experiments has been to determine the changes in refractive index produced by shock densification in order to use these data to deduce the pressure and temperature histories of naturally shocked lunar and terrestrial glasses. The fused silica has been of special significance because of its simple composition and because other investigators have studied its shock densification and equation of state (e.g. Arndt et al. [1971] and Wackerle [1962]). Permanent increases in density of silica glass were first observed by Bridgman and Simon [1953] in static isothermal compression studies; they observed a threshold of densification of approximately $100 \mathrm{~kb}$. Subsequent static high-pressure studies of fused silica by Roy and Cohen [1961], Kennedy et al. [1962], Craig [1969], and others have yielded similar results but with thresholds of

${ }^{1}$ Contribution 1957, Division of Geological and Planetary Sciences, California Institute of Technology, Pasadena 91109. Lunar Science Institute Contribution 41 .

Copyright $(1971$ by the American Geophysical Union. densification of less than $60 \mathrm{~kb}$. Recently, Bless [1970] observed comparable irreversible densification of fused silica in isentropic magnetic pinch experiments to more than $100 \mathrm{~kb}$.

$\mathrm{SiO}_{4}$ tetrahedra, which comprise fused silica, are the major network-forming polyhedra in all silicate glasses; the other glasses differ from fused silica by the presence of such networkmodifying cations as $\mathrm{Mg}^{++}, \mathrm{Fe}^{++}, \mathrm{Ca}^{++}, \mathrm{Na}^{+}$, and $\mathrm{K}^{+}$, which occupy possible 6-, 8-, and 12-fold sites in the irregular network. As those large cations are added to the silica glass, the threshold pressure of irreversible densification progressively decreases. We therefore suspected that shock compression of fused silica might generally provide a pattern for the behavior of the tektite and soda-lime glasses.

\section{Sample Preparation and Experimental Procedures}

The glasses studied were tektite (indochinite IC298 from American Meteorite Laboratory), soda-lime (cover glass 19130 from Kimble $(\operatorname{Exax})$ ), and fused silica (General Electric schlieren grade type 151). Chemical compositions of the first two glasses were quoted in Ahrens et al. [1970]. Initial zero-pressure densities were $2.44 \pm 0.02 \mathrm{~g} / \mathrm{cm}^{3}, 2.43 \pm 0.02$ 
$\mathrm{g} / \mathrm{cm}^{3}$ (R. L. Fleischer, private communication to TJA, 1970), and $2.204 \pm 0.003 \mathrm{~g} / \mathrm{cm}^{3}$ (present study) respectively.

The samples were machined into thin wafers from which disks $4.75 \mathrm{~mm}$ in diameter were cored; the disks were ground and polished to a final thickness of $0.15 \mathrm{~mm}$. The finished specimens were loaded into aluminum '2024' or stainless steel '304' cylindrical containers of $19-\mathrm{mm}$ diameter and 7-mm thickness. The sample containers were in turn mounted into massive aluminum '2024' or stainless steel ' 304 ' cylindrical target blocks some $10 \mathrm{~cm}$ in diameter and $8 \mathrm{~cm}$ thick.

Shock waves were induced in the samples by impacting the target with $2.5-\mathrm{mm}$ - and 5 -mmthick metal flyer plates of brass $(\mathrm{Cu} 65 \%$,

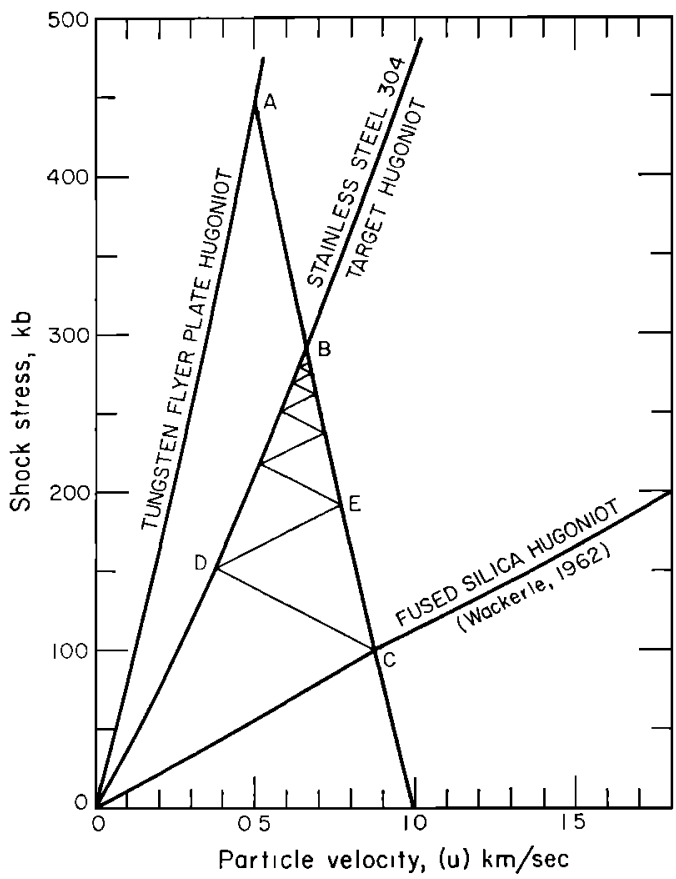

Fig. 1. Graphical representation of the 'impedance matching' method of determining shock pressures using as an example an impact of a tungsten flyer plate into a stainless steel target containing a specimen of fused silica at a freeflight velocity of $1 \mathrm{~km} / \mathrm{sec} . B$ is the peak pressure attained in the target; $C$ is the initial pressure in the fused silica. $C D, D E$ represent shock reverberations in the fused silica that progressively increase its shock pressure until the peak pressure $B$ of the target is reached. The time required to reach peak pressure is approximately $0.3 \mu$ sec.
$\mathrm{Zn} 33 \%, \mathrm{~Pb} 2 \%$ ) or tungsten alloy (W 90\%, $\mathrm{Ni} 7 \%, \mathrm{Cu} 3 \%$ ) imbedded in the front surface of Lexan (plastic) projectiles. The projectiles were launched using the 1-meter-long, 2-cmdiameter Caltech propellant gun to velocities in the range of 0.4 to $1.5 \mathrm{~km} / \mathrm{sec}$. Projectile velocities were measured using a 'free-flight' method described by Hörz and Ahrens [1969].

The measured velocity, the Hugoniot of the target material, the Hugoniot of the flyer plate, and the Hugoniot of the sample were used in a graphical 'impedance matching' method of determining the shock pressure transmitted into the target and the sample (Figure 1 and Duvall and Fowles [1963]). From consideration of Figures 1 and 2, it is clear that for an impact at $1 \mathrm{~km} / \mathrm{sec}$ of a tungsten alloy flyer plate into a stainless steel ' 304 ' target, shock-wave reverberations across the sample raised its pressure to the peak pressure of the target before a rarefaction wave originating from the black surface of the flyer plate caught up to and attenuated the peak shock stress. The period of maximum shock pressure in the samples, before rarefaction attenuation, was approximately 1 or $2 \mu \mathrm{sec}$; these values correspond to the twoway shock transit times through $2.5-\mathrm{mm}$ and 5 -mm flyer plates, respectively.

The accuracy of measurement of the projectile velocity is better than $1 \%$. However, errors due to inaccuracy of the Hugoniot curves and application of the graphical impedance match solution increase the errors in the shock pressures to $\pm 3 \%$.

After shock loading, the sample containers were machined open to expose the shocked specimens. The character of the specimens varied from coarsely fractured to finely powdered. For refractive index measurements, some care was taken to remove sample material from the centers of the specimen disks, in case effects of the disk edges on the shock pulse might have resulted in a radial change in pressure. Refractive indices were measured by standard immersion techniques at Caltech and by interference microscopy at the laboratory of E. C. T. Chao, United States Geological Survey, Washington, D.C.

\section{Experimental Results}

The data on shock pressure and refractive index are given in Tables 1,2 , and 3 for tektite 
glass, soda-lime glass, and fused silica, respectively. Graphical plots of these data (Figures 3,4 , and 5) correlate a range of refractive index within a specimen with the peak shock pressure to which the specimen was subjected.

For shock compression below $80 \mathrm{~kb}$ for fused silica and $40 \mathrm{~kb}$ for tektite and soda-lime glasses, the densification appears reversible, since the changes in refractive index are within 0.0025 of the starting values. Index increases of $0.01,0.04$, and 0.06 are observed for sodalime, tektite, and silica glasses shocked to pressures of 80,130 , and $140 \mathrm{~kb}$, respectively. For soda-lime glass in the pressure range 80 to $230 \mathrm{~kb}$, there is an equivalent decrease in index to the subinitial value $n=1.5211$. Similar behavior is exhibited by fused silica shocked to pressures between 140 and $460 \mathrm{~kb}$; however, for fused silica there is a refractive index plateau for material shocked to pressures between 140 and $300 \mathrm{~kb}$, an index decrease of 0.025 for material shocked to pressures between 300 and $310 \mathrm{~kb}$, and a low-density glass for material shocked to pressures up to $460 \mathrm{~kb}$.

\section{Discussion}

Figures 6 and 7 show the Hugoniot and release adiabat data for fused silica [Rosenberg et al., 1968]. The Hugoniot data reflect the lowpressure, mixed-phase, and high-pressure regimes that McQueen et al. [1963] recognized as representing, respectively, fused silica, a mixture of fused silica and a high-density phase, and the high-density phase, presumably stishovite [DeCarli and Milton, 1965]. Wackerle [1962] recognized the Hugoniot elastic limit (HEL) of fused silica as $98 \mathrm{~kb}$; the discontinuity that he observed at $262 \mathrm{~kb}$ represents complete transformation to some form of the high-density phase. Postshock densities were calculated from the measured refractive indices of fused silica using a modified Gladstone-Dale law:

$$
(n-1) / \rho=\left(n_{0}-1\right) / \rho_{0}
$$

where $n, n_{o}, \rho$, and $\rho_{o}$ are the initial and final refractive indices and densities, respectively, Anderson and Schreiber [1965] have found that refractive index-density relationships of silica polymorphs are quite close $( \pm 1.5 \%)$ to the Gladstone-Dale law at low density. Specific volumes calculated from the postshock densities range from 0.406 to $0.453 \pm 0.004 \mathrm{~cm}^{3} / \mathrm{g}$; this range is comparable to that of the releaseadiabat specific volumes illustrated in Figure 7 (these data are tabulated in Table 4). These

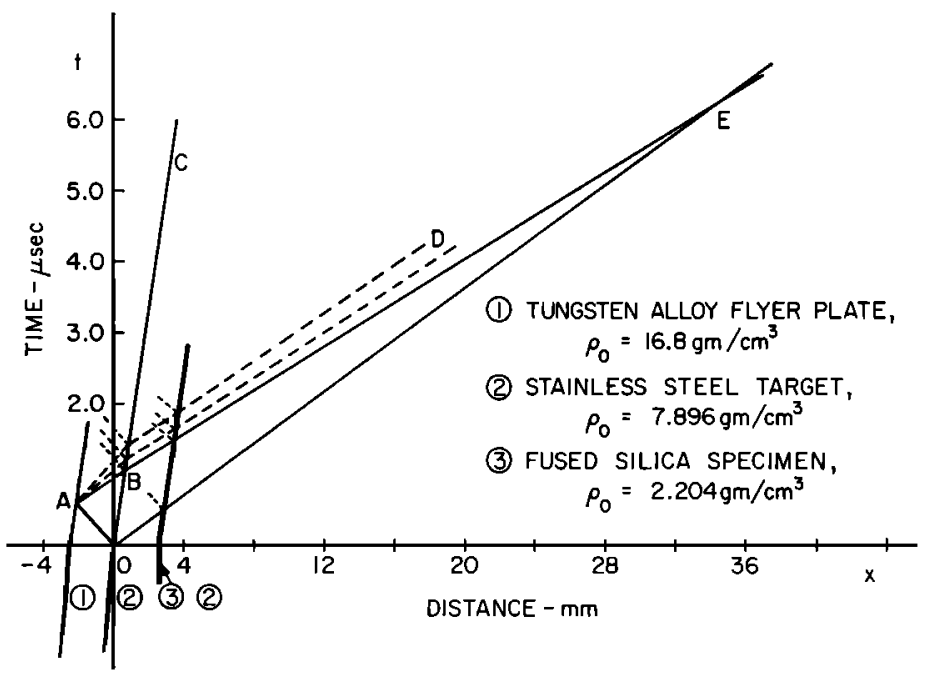

Fig. 2. $x-t$ diagram of the impact of a $2.5-\mathrm{mm}$ tungsten alloy flyer plate (1) against a stainless steel 304 target (2) containing a fused silica sample disk (3) $O E$ is the trajectory of shock wave in the target, $O A$ is the trajectory of shock wave in flyer plate, $A$ is the pole of centered rarefaction wave, $A B E$ and $A D$ are rarefaction waves, and $O B C$ is the trajectory of advance of flyer plate-target interface. Attenuation of the shock pulse in the sample starts at $1 \mu \mathrm{sec}$ after the initial shock and $0.7 \mu \mathrm{sec}$ after the sample has reached peak pressure. 
Table 1. Refractive Index Measurements of Shock-Loaded Tektite Glass

\begin{tabular}{ccc}
\hline $\begin{array}{c}\text { Shot } \\
\text { Number }\end{array}$ & $\begin{array}{c}\text { Shock } \\
\text { Pressure, kb }\end{array}$ & $\begin{array}{c}\text { Refractive } \\
\text { Index }(n)\end{array}$ \\
\hline$\ldots$ & 0 & $1.5051 \pm 0.0002^{a}$ \\
& & $1.5055 \pm 0.0005$ \\
119 & $43 \pm 2$ & $1.5060 \pm 0.0005$ \\
120 & $56 \pm 3$ & $1.5087 \pm 0.0005$ \\
122 & $53 \pm 2$ & $1.5065 \pm 0.0005$ \\
123 & $32 \pm 2$ & $1.5055 \pm 0.0005$ \\
124 & $28 \pm 2$ & $1.5055 \pm 0.0005$ \\
142 & $133 \pm 10$ & $1.5419 \pm 0.0002^{a}$ \\
& $38 \pm 2$ & $1.5404 \pm 0.0005$ \\
143 & $38 \pm 0.0005$ \\
144 & $42 \pm 3$ & $1.5075 \pm 0.0005$ \\
152 & $112 \pm 2$ & $1.5247 \pm 0.0002^{a}$ \\
145 & $83 \pm 4$ & $1.5137 \pm 0.0005$ \\
\end{tabular}

- Measurements by interference microscopy; all others by standard immersion methods.

results indicate that there is some relationship between postshock density and range of stability of the different phases along the Hugoniot. At peak pressure, the recovered fused silica is not irreversibly compressed to a maximum density; the final state appears to be very dependent on the release-adiabat path from the peak pressure. It is interesting that adiabatic release from the highest shock pressure, $460 \mathrm{~kb}$, results in a glass of lower postshock density, $2.27 \mathrm{~g} / \mathrm{cm}^{3}$, than release from $290 \mathrm{~kb}, 2.44 \mathrm{~g} / \mathrm{cm}^{3}$. This may arise by reconstructive transformation of a stishovitelike material to a high-density glass and subsequent annealing resulting from the high postshock temperature.

Besides annealing effects, the release-adiabat specific volumes that correspond to the ambient pressure, postshock temperature states will be slightly higher (by the thermal expansion) than those inferred from the room temperature index data. This difference is negligible $(\sim 0.2 \%)$ on the accuracy level of the present study.

We have observed reversible compression of the silica glass to $80 \pm 3 \mathrm{~kb}$; this result is compatible with the dynamic HEL value observed by Wackerle [1962]. A somewhat lower pressure threshold for permanent densification of less than $60 \mathrm{~kb}$ has been obtaind by Bless [1970] in magnetic pinch experiments under rapid isentropic conditions. Arndt et al. [1971] have studied samples recovered from single shock experiments and obtained an apparent elastic limit of $55 \pm 5 \mathrm{~kb}$; they also observed a decrease in refractive index for fused silica shocked to pressures of 140 to $200 \mathrm{~kb}$ (Figure 5). In our experiments, sample shock pressures were attained through multiple shock reflection rather than single shock (the $460 \mathrm{~kb}$ shock of Arndt et al. [1971] was also produced by multiple shock reflection). Differences between postshock temperatures calculated for the two techniques are illustrated in Table 5, compared with those calculated by Wackerle [1962] for single shock experiments on the basis of different assumptions about release adiabats.

As stated above, the tektite and soda-lime glasses are modifications of fused silica caused by the addition of large network-modifying cations; the elastic limits and permanent compressibilities of the glasses should be lower than those of fused silica because of the effects of such cations on the stability of the glass structural network of silica (plus alumina for the tektite and soda-lime) polyhedra. Our results do show the elastic limit (here taken to mean no irreversible compaction) to be $40 \pm 5$ $\mathrm{kb}$ for each of these glasses. Dremin and Adadurov [1964] observed a dynamic elastic limit (HEL) ranging from 36 to $73 \mathrm{~kb}$, depending on sample thickness, for a soda-lime glass of only slightly different composition from ours; the data are obviously compatible.

The permanent densification observed for those glasses above their elastic limits may represent compaction like that observed under

TAbLe 2. Refractive Index Measurements o Shock-Loaded Soda-Lime Glass

\begin{tabular}{cccc}
\hline & & \multicolumn{2}{c}{ Refractive Index $(n)$} \\
\cline { 3 - 4 } $\begin{array}{c}\text { Shot } \\
\text { Number }\end{array}$ & $\begin{array}{c}\text { Shock } \\
\text { Pressure, } \\
\text { kb }\end{array}$ & $\begin{array}{c}\text { Interfer- } \\
\text { ence } \\
\text { Method }^{2}\end{array}$ & Immerson Method \\
\hline$\ldots$ & $\mathbf{0}$ & $\mathbf{1 . 5 2 3 9}$ & $1.5242 \pm 0.0005$ \\
IV & 57 & 1.5275 & $1.5285 \pm 0.0005$ \\
150 & $62 \pm 2$ & 1.5249 & $1.5275 \pm 0.0009$ \\
151 & $79 \pm 2$ & 1.5367 & $1.5312 \pm 0.0010$ \\
148 & $113 \pm 2$ & 1.5220 & $1.5230 \pm 0.0010$ \\
147 & $118 \pm 2$ & 1.5229 & $1.5249 \pm 0.0010$ \\
164 & $134 \pm 3$ & 1.5239 & $1.5233 \pm 0.0009$ \\
167 & 230 & 1.5211 & $1.5211 \pm 0.0011$ \\
179 & $93 \pm 2$ & 1.5261 & $1.5272 \pm 0.0010$ \\
180 & $89 \pm 2$ & 1.5262 & $1.5266 \pm 0.0010$ \\
\hline
\end{tabular}

- Error, \pm 0.0002 . 


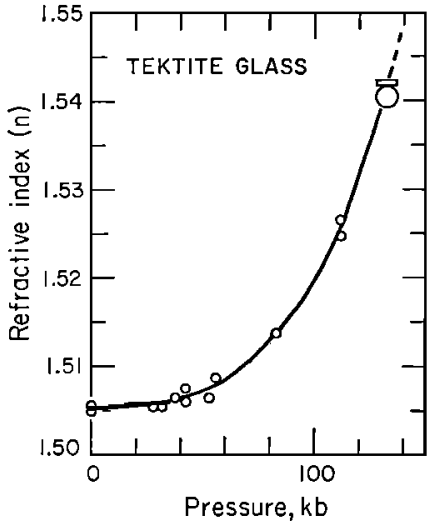

Fig. 3. Refractive index-shock pressure graph of tektite glass data. The sizes of the open datapoint circles indicate the precision of the data.

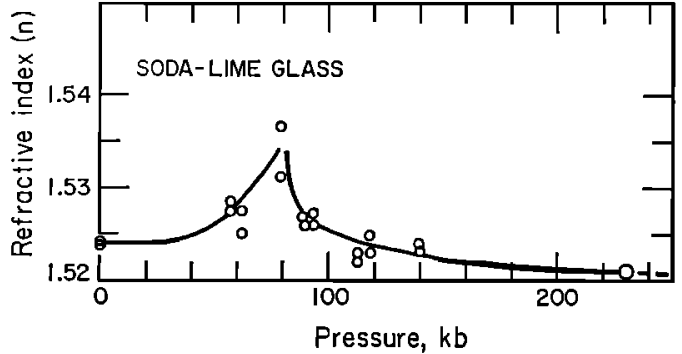

Fig. 4. Refractive index-shock pressure graph of soda-lime glass data. The sizes of the open data-point circles indicate the precision of the data.

TABLE 3. Refractive Index Measurements of Shock-Loaded Fused Silica

\begin{tabular}{|c|c|c|c|c|}
\hline \multirow[b]{2}{*}{$\begin{array}{c}\text { Shot } \\
\text { Number }\end{array}$} & \multirow[b]{2}{*}{$\begin{array}{c}\text { Shock Pressure, } \\
\text { kb }\end{array}$} & \multicolumn{3}{|c|}{ Refractive Index $(n)$} \\
\hline & & $\begin{array}{l}\text { Interference } \\
\text { Method }\end{array}$ & $\begin{array}{c}\text { Immersion }^{b} \\
\text { Method }\end{array}$ & Average \\
\hline$\cdots$ & 0 & 1.4579 & 1.4588 & 1.4584 \\
\hline $\mathrm{R}^{\circ} \mathrm{O}$ & 170 & 1.4894 & 1.4855 & 1.4875 \\
\hline $\mathrm{R}^{\circ}$ & 198 & $\begin{array}{l}1.5180 \\
1.5116\end{array}$ & 1.5070 & 1.5122 \\
\hline $\mathrm{R} 5^{d}$ & 160 & $\begin{array}{l}1.4902 \\
1.4805\end{array}$ & & 1.4851 \\
\hline 156 & $92 \pm 2$ & & 1.4828 & 1.4828 \\
\hline 157 & $132 \pm 5$ & $\begin{array}{l}1.5109 \\
1.5203\end{array}$ & 1.4930 & 1.5081 \\
\hline 158 & $82 \pm 2$ & $\begin{array}{l}1.4570 \\
1.4590\end{array}$ & 1.4626 & 1.4595 \\
\hline 159 & $81 \pm 2$ & 1.4606 & 1.4628 & 1.4617 \\
\hline R7• & 192 & $\begin{array}{l}1.4908 \\
1.4885 \\
1.5147\end{array}$ & & 1.4980 \\
\hline $\mathrm{R}^{c}$ & 136 & $\begin{array}{l}1.5036 \\
1.5122\end{array}$ & & 1.5079 \\
\hline R9• & 314 & 1.4794 & & 1.4794 \\
\hline R10 & 290 & $\begin{array}{l}1.5068 \\
1.5096\end{array}$ & & 1.5082 \\
\hline R11 & 242 & $\begin{array}{l}1.5057 \\
1.5155\end{array}$ & & 1.5106 \\
\hline R12。 & 200 & $\begin{array}{l}1.4884 \\
1.5191\end{array}$ & & 1.5038 \\
\hline $\mathrm{R}^{\circ} 3^{\circ}$ & 180 & $\begin{array}{l}1.4902 \\
1.4702\end{array}$ & & 1.4802 \\
\hline $\mathrm{R}^{\prime} 4^{d}$ & 376 & $\begin{array}{l}1.4774 \\
1.4638\end{array}$ & & 1.4706 \\
\hline $\mathbf{R}^{d}{ }^{d}$ & 418 & $\begin{array}{l}1.4617 \\
1.4818\end{array}$ & & 1.4718 \\
\hline $\mathrm{R}^{16^{d}}$ & 460 & $\begin{array}{l}1.4756 \\
1.4703\end{array}$ & & 1.4730 \\
\hline
\end{tabular}

- Error, \pm 0.0002 .

Error, \pm 0.0010 .

- Brass flyer plate used.

$d$ Tungsten alloy flyer plate used. 


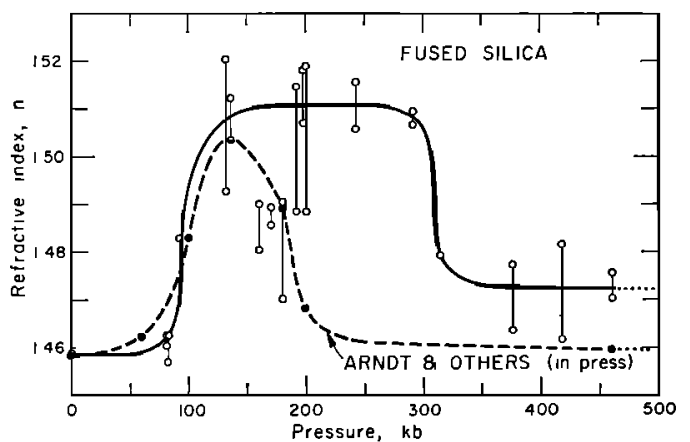

Fig. 5. Refractive index-shock pressure graph of fused silica data. The sizes of the open datapoint circles indicate the precision of the data; lines joining circles indicate the range of refractive index observed in some specimens. The filled circles are the data of Arndt et al. [1971], which have been reproduced for comparison.

isothermal static compression by Bridgman and Simon [1953] and others. It is equivalent to the proportion of the shock compression that has become locked into the glass upon adiabatic release to zero pressure. We do not know whether this shock-produced irreversible densification is in part represented by the formation of a high-density phase (the pressures are within the mixed-phase regimes of the respective Hugoniots), since we have not observed any crystalline stishovite in these samples.

The behaviors of the fused silica and sodalime glass at pressures above 140 and $80 \mathrm{~kb}$, respectively, are anomalous; although the postshock specific volumes calculated for fused silica are compatible with release-adiabat data (Figure 7 and Rosenberg et al. [1968]), the interesting double-valued nature of the refractive index-pressure graphs does warrant discussion.

For the soda-lime glass one explanation may be that the refractive index decrease above 80 $\mathrm{kb}$ is an annealing effect of high shock and postshock temperatures. Ahrens et al. [1970] calculated these temperatures for this soda-lime glass to pressures of $100 \mathrm{~kb}$; the maximum calculated temperature increase was only $55^{\circ} \mathrm{C}$ at $80 \mathrm{~kb}$. However, the release adiabat data for fused quartz suggest that their values may be an extreme lower bound to the actual postshock temperature. Chao and Bell [1968] and Bell and Chao [1969] have carried out experiments on the annealing effects of high tempera-

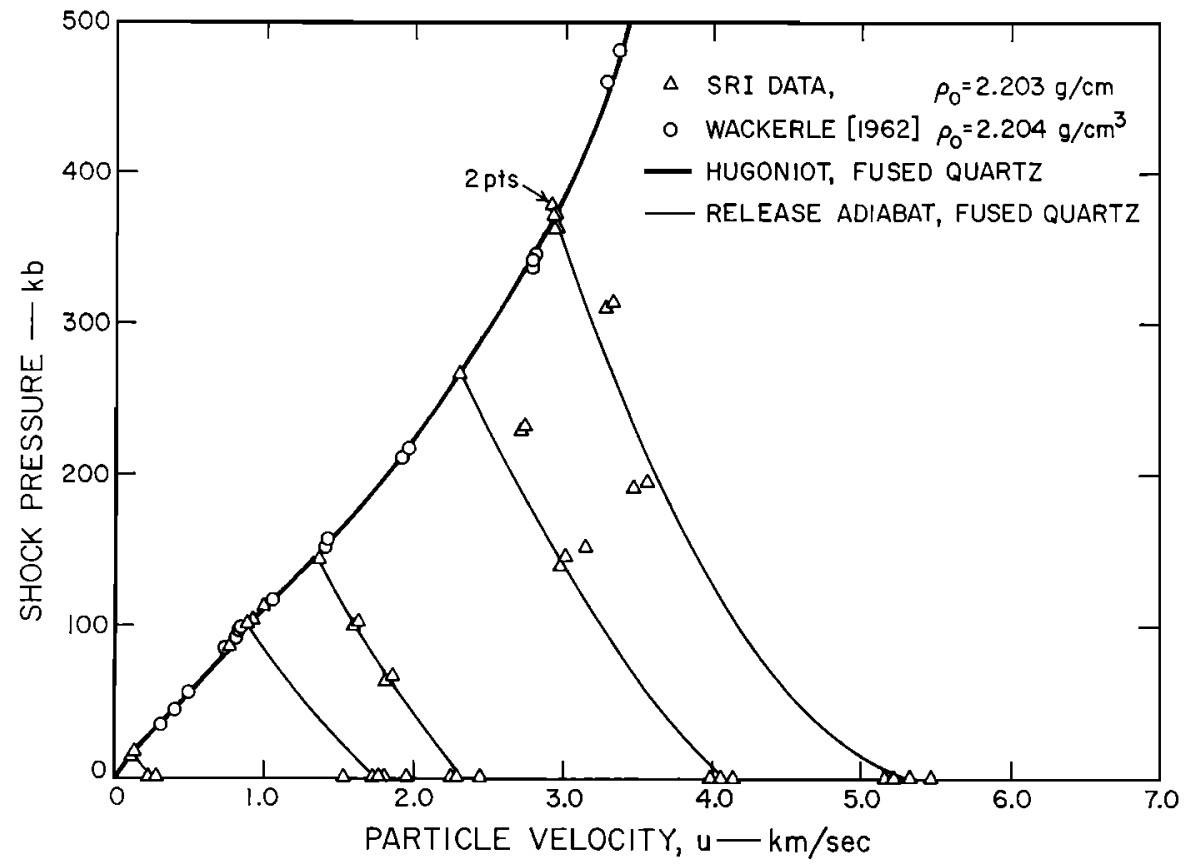

Fig. 6. Shock pressure-particle velocity Hugoniot and release adiabat data for fused silica (reproduced from Rosenberg et al. [1968]). 


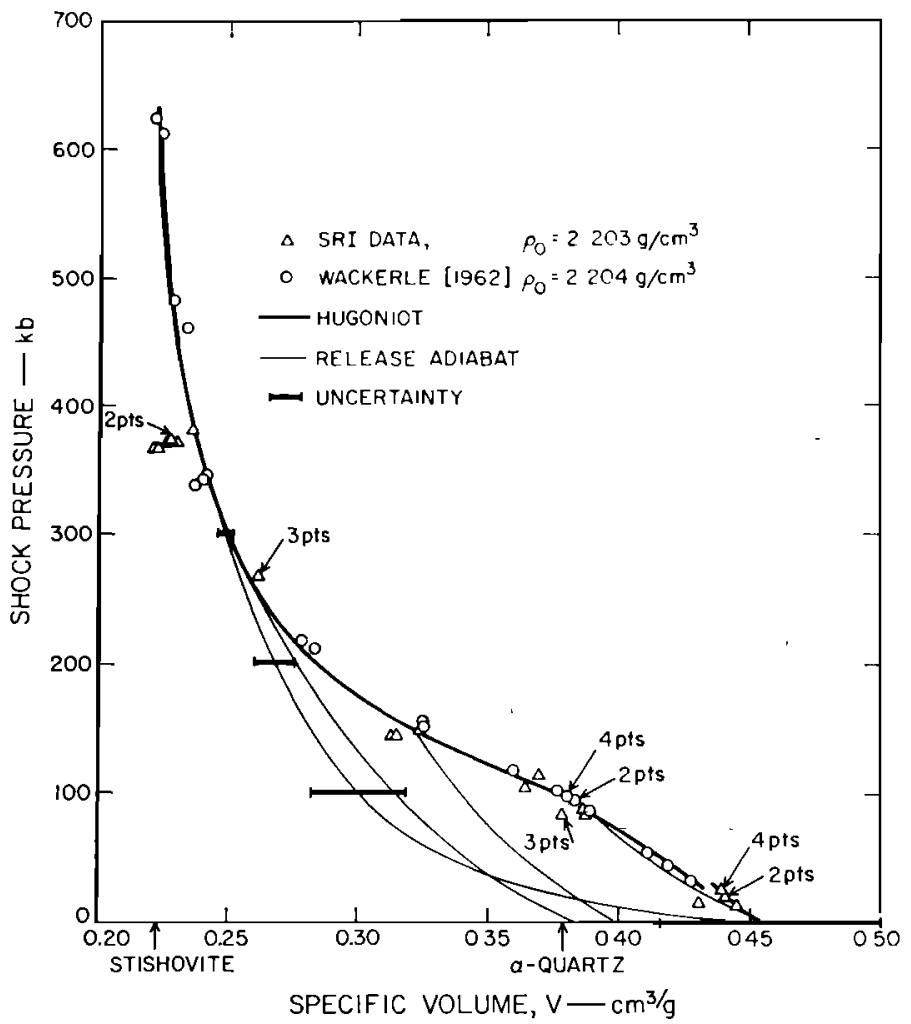

Fig. 7. Shock pressure-specific volume Hugoniot and release adiabat data for fused silica (reproduced from Rosenberg et al. [1968]). Specific volumes calculated from our fused silica refractive index data for material shocked to pressures up to $460 \mathrm{~kb}$ according to the Gladstone-Dale law fall within the range 0.4 to $0.45 \mathrm{~cm}^{3} / \mathrm{g}$.

tures on shock-densified silicate glasses and found that temperatures of the order of $500^{\circ} \mathrm{C}$ and higher are required to anneal feldspar glasses in times of a few seconds. We can either conclude that: (1) the lower-bound calculated temperatures do not adequately represent the achieved temperatures, and the temperatures are sufficient for annealing; (2) the high shock pressure has a large effect on the temperature required to anneal the glass; or (3) annealing is not a principal mechanism in the index decrease.

For fused silica, another explanation of the behavior of the refractive index-pressure graphs at high pressure must be considered. We have noted that the pressure range 140 to $300 \mathrm{~kb}$ is represented by almost a plateau in refractive index. This range is essentially within the mixedphase regime of the Hugoniot; if a mixture of the low-pressure fused silica phase and the high-pressure stishovitelike phase persisted after pressure release, we should expect a continuous increase in refractive index for pressures to $300 \mathrm{~kb}$. However, if the high-pressure phase relaxed to a low-density glass by adiabatic release and postshock annealing, we should expect an averaging of the refractive indices of a severely compacted material and a lowdensity glass; the result could be the index plateau we observe. Since powder-diffraction studies of some recovered material using 114.6$\mathrm{mm}$ Debye-Scherrer $\mathrm{X}$-ray cameras did not reveal any stishovite, we may assume that adiabatic release resulted in complete relaxation of the compressed material to a low-density glass. This might explain the sharp drop in refractive index of material shocked to pressures within the range 300 to $310 \mathrm{~kb}$, as well as the low refractive index plateau for material shocked to even higher pressures. Thus shock loading to $300 \mathrm{~kb}$ or higher transforms the low- 
Table 4. Postshock Specific Volumes of Fused Silica

(Calculated by the Gladstone-Dale Law)

\begin{tabular}{|c|c|c|c|}
\hline $\begin{array}{l}\text { Shot } \\
\text { Num- } \\
\text { ber }\end{array}$ & $\begin{array}{l}\text { Shock } \\
\text { Pressure, } \\
\text { kb }\end{array}$ & $\begin{array}{l}\text { Postshock } \\
\text { Volume, } \\
\mathrm{cm}^{3} / \mathrm{g}\end{array}$ & $\begin{array}{c}\text { Release Adiabat } \\
\text { Volume, } \\
\text { cm }{ }^{2} / \mathrm{g}\end{array}$ \\
\hline$\cdots$ & $\mathbf{0}$ & 0.454 & \\
\hline 159 & 81 & $0.450 \pm 0.001$ & $0.454 \pm 0.03$ \\
\hline 158 & 82 & 0.453 & \\
\hline 156 & 92 & 0.431 & \\
\hline 157 & 132 & 0.409 & \\
\hline R8 & 136 & $0.410 \pm 0.003$ & $0.40 \pm 0.03$ \\
\hline R5 & 160 & 0.429 & \\
\hline R1 & 170 & 0.427 & \\
\hline R13 & 180 & 0.433 & \\
\hline R7 & 192 & 0.418 & \\
\hline R2 & 198 & 0.406 & \\
\hline R12 & 200 & 0.413 & \\
\hline R11 & 242 & $0.407 \pm 0.004$ & $0.385 \pm 0.03$ \\
\hline R10 & 290 & 0.409 & \\
\hline R9 & 314 & $0.434 \pm 0.004$ & $0.45 \pm 0.04$ \\
\hline R14 & 376 & 0.442 & \\
\hline R15 & 418 & 0.441 & \\
\hline R16 & 460 & $0.440 \pm 0.003$ & $0.45 \pm 0.04$ \\
\hline
\end{tabular}

a See Figure 7.

pressure 4-fold coordinated silica network to a high-pressure 6-fold coordinated network that, on adiabatic release and postshock annealing, decompresses to a low-density glass with tetrahedrally coordinated silica.

\section{Postshock Temperatures}

The Hugoniot and release adiabat data in Figure 7 have been used to calculate postshock temperatures for fused silica shocked to states in the 100 - to $500-\mathrm{kb}$ pressure range. Temperatures have been calculated for both multipleshock reflection-type experiments (case 1 of Table 5) and single-shock experiments (case 2 of Table 5).

For case 2 we assume the net thermal energy resulting from shock compression followed by adiabatic release is given by

$$
E_{2}=\int_{298^{*} \mathrm{~K}}^{T^{*} \mathrm{~K}} C p d T
$$

which equals the difference between the shock energy given by the Rankine-Hugoniot equation

$$
E_{\mathrm{o}}=(1 / 2)\left(P+P_{0}\right)\left(V_{0}-V\right)
$$

and the adiabatic release energy

$$
E_{R}=-\int_{\nabla_{0^{\circ}}}^{V} P d V
$$

In those equations, $P_{0}$ and $V_{0}$ represent initial pressure and specific volume respectively, $V$ is specific volume at peak pressure, $P, T$ is postshock temperature in degrees Kelvin, $C p$ is the specific heat of fused silica at constant pressure, and $V_{0}^{\prime}$ is the postshock volume.

For case 1, numerous reverberations of the shock pulse across the sample add successively smaller increments to the initial sample pressure until peak pressure is reached (Figure 1). As a result the total shock energy is given by

$$
E_{\varepsilon}=\frac{1}{2} \sum_{k=0}^{\infty}\left(P_{k+1}+P_{k}\right)\left(V_{k}-V_{k+1}\right)
$$

\begin{tabular}{|c|c|c|c|c|c|}
\hline \multirow[b]{2}{*}{$\begin{array}{c}\text { Shock } \\
\text { Pressure, kb }\end{array}$} & \multicolumn{2}{|c|}{ Case 1 } & \multicolumn{2}{|c|}{ Case $2^{b}$} & \multirow[b]{2}{*}{$T,{ }^{\circ}{ }^{\circ} \mathrm{C}$} \\
\hline & $\begin{array}{c}E_{1} \\
\text { Thermal Energy, } \\
\text { cal/mole }\end{array}$ & $T,{ }^{\circ} \mathrm{C}$ & $\begin{array}{c}E_{2} \\
\text { Thermal Energy, } \\
\text { cal/mole }\end{array}$ & $T,{ }^{\circ} \mathrm{C}$ & \\
\hline 100 & 650 & 80 & 650 & 80 & 0 \\
\hline 150 & 5,720 & 450 & 5,720 & 450 & 0 \\
\hline 250 & 18,070 & 1170 & 19,050 & 1220 & 0 \\
\hline 300 & 19,830 & 1260 & 23,920 & 1480 & 470 \\
\hline 400 & 26,200 & 1590 & 38,610 & 2180 & 1860 \\
\hline 500 & 28,340 & 1700 & 53,690 & 2820 & 3310 \\
\hline
\end{tabular}

TABLE 5. Postshock Temperatures of Fused Silica

(Calculated Using the Hugoniot and Release Adiabat Data in Figure 7)

- For multiple-shock reflection-type experiments.

b For single-shock experiments.

- Postshock temperatures from Wackerle [1962]. 
The states $P_{k}, V_{k},(k \neq 0)$ represent the series of shock pressures and specific volumes achieved along the infinite series of Hugoniots centered at states $P_{k-1}, V_{k-1}$ that are achieved via wave reverberation in the sample. The total shock energy for case 1 is less than the shock energy for case 2. Assuming that the fused quartzstishovite phase change occurs reversibly (as is certainly closely valid in the present experiments), the net thermal postshock energy is given by

$$
E_{1 \mathrm{Or} 2}=\int_{288^{\circ} \mathrm{K}}^{T^{\circ} \mathrm{K}} C p d T=E_{s}-E_{R}
$$

where $E$, is given by equations 5 and 3 for cases 1 and 2. The energy term corresponding to the work done against ambient pressure on expansion from $298^{\circ} \mathrm{K}$ to $T$ is negligible. Numerical integration of equation 6 for postshock energies yields the values given in Table 5. The empirical formula for the molal heat-capacity equation of fused silica

$$
\begin{aligned}
& C p\left(\mathrm{cal} / \mathrm{mole}^{\circ} \mathrm{K}\right) \\
& =13.38+3.68 \times 10^{-3} \mathrm{~T}-3.45 \times 10^{5} \mathrm{~T}^{-2}
\end{aligned}
$$

given by Kelley [1960] is used in equation 6 to yield the postshock temperature given in Table 5. Uncertainties in $E_{n}$ reflecting the uncertainties in the release adiabats give rise to errors in the calculated postshock temperatures of $\sim 10 \%$ at low pressures, ranging to $\sim 20 \%$ at $\sim 500 \mathrm{~kb}$.

The postshock temperatures calculated by Wackerle [1962] for single-shock experiments are much lower than those we have calculated for pressures up to $300 \mathrm{~kb}$ but are comparable to our single-shock temperatures at higher pressures. The differences in the calculated results arise to a minor degree from Wackerle's [1962] assumption of a constant specific heat $C v$ and constant $(\partial P / \partial E) v$; in addition, Wackerle ignored the elastic compressions and performed numerical integration along extrapolated 'equilibrium' curves. However, the major factor producing the differences in postshock temperature is our use of the new release adiabat data in Figure 7. Since below $300 \mathrm{~kb}$ the actual release curves lie below the Hugoniot rather than above, as is implicit in Wackerle's formulation, the differences in $T$ are great at the lower pressures. At much higher pressures the assumptions in Wackerle's calculation should, within the present state of our knowledge, be approximately valid.

On the basis of annealing studies on fused silica, Arndt et al. [1971] have found that temperatures of $300^{\circ} \mathrm{C}$ have a significant effect on the relaxation of densified fused silica. Therefore, in view of our calculated temperatures, annealing could play a major role in causing the drop in refractive index of fused silica shocked to $300 \mathrm{~kb}$ and higher pressures.

\section{Conclusions}

1. Variation in the percentage of networkforming polyhedra of silica and alumina affects the threshold of densification and the maximum permanent compression that may result from shock loading. The Hugoniot elastic limit is compatible with the threshold of permanent densification.

2. Postshock annealing may be a mechanism for the relaxation of high-density glasses to low-density glasses for material shocked to below $150 \mathrm{~kb}$. It is certainly active for shock strengths above this level.

3. Transformation of the low-pressure phase to a high-pressure stishovitelike phase followed by adiabatic release to a low-density glass probably occurs for shock compressions up to $\sim 300 \mathrm{~kb}$. Above this pressure, postshock annealing at temperatures in excess of $1000^{\circ} \mathrm{C}$ would account for the low-density glass that is recovered.

4. Despite the double-valued nature of the fused silica and soda-lime index versus shock pressure relations (Figures 4 and 5), if the pressure regime of naturally shocked glasses can be determined by other means, our data should be useful in obtaining pressure and temperature histories of those glasses.

Acknowledgments. We especially appreciate E. C. T. Chao's hospitality and assistance in carrying out the interference microscopy and R. L. Fleischer's kindness in providing some of the specimen material. Contributions were made to the experiments by D. Johnson, J. Kleeman, and J. Lower. Discussions of the project with A. L. Albee, E. C. T. Chao, B. Kamb, E. Shoemaker, L. T. Silver, and H. P. Taylor were also helpful.

The research was supported at California In- 
stitute of Technology by NASA grant NGL-05002-105. Publication was, in part, supported by NASA contract NSR 09-051-001.

\section{REFERENCES}

Ahrens, T. J., R. L. Fleischer, P. B. Price, and R. T. Woods, Erasure of fission tracks in glasses and silicates by shock waves, Earth Plonet. Sci. Lett., 8, 420, 1970.

Anderson, O. L., and E. Schreiber, The relation between refractive index and density of minerals related to the earth's mantle, J. Geophys. Res., 70, 1463, 1965.

Arndt, J., U. Hornemann, and W. F. Müller, Shock-wave densification of silica glass, Phys. Chem. Glasses, in press, 1971.

Bell, P. M., and E. C. T. Chao, Annealing experiments with naturally and experimentally shocked feldspar glasses, Carnegie Inst. Wash. Yr. Book $68,336,1969$.

Bless, S. J., The effects of magnetic pinch pressure on boron nitride, cadmium sulfide, graphite, silica glass, and some other materials, Ph.D. thesis, Massachusetts Institute of Technology, Boston, 1970.

Bridgman, P. W., and I. Simon, Effect of very high pressure on glass, J. Appl. Phys., 24, 405, 1953.

Chao, E. C. T., and P. M. Bell, Annealing characteristics of dense feldspar glass, Carnegie Inst. Wash. Yr. Book 67, 126, 1968.

Craig, H., Density and refractive index hysteresis in compressed silicate glasses, J. Geophys. Res., 74, 4910, 1969.

DeCarli, P. S., and D. J. Milton, Stishovite: Synthesis by shock wave, Science, 147, 144, 1965.
Dremin, A. N., and G. A. Adadurov, The behavior of glass under dynamic loading, Soviet Phys. Solid State, 6, 1379, 1964.

Duvall, G. E., and G. R. Fowles, High Pressure Physics and Chemistry, vol. 2, p. 209, McGrawHill, New York, 1963.

Hörz, F., and T. J. Ahrens, Deformation of experimentally, shocked biotite, Amer. J. Sci., 267, $1213,1969$.

Kelley, K. K., Contributions to the data on theoretical metallurgy, XIII, High-temperature heatcontent, heat-capacity, and entropy data for the elements and inorganic compounds, U.S. Bur. Mines Bull. 584, 160, 1960.

Kennedy, G. C., G. J. Wasserburg, H. C. Heard, and R. C. Newton, The upper three-phase region in the system $\mathrm{SiO}_{2}-\mathrm{H}_{2} \mathrm{O}$, Amer. J. Sci., 260, 501, 1962.

McQueen, R. G., J. N. Fritz, and S. P. Marsh, On the equation of state of stishovite, J. Geophys. Res., 68, 2319, 1963.

Rosenberg, J. T., T. J. Ahrens, and C. F. Petersen, Dynamic properties of rocks, report prepared for Headquarters, Defense Atomic Support Agency, Washington, D. C., at Shock and High Pressure Physics Department, Stanford Research Institute, Menlo Park, California, July, 1968.

Roy, R., and H. M. Cohen, Effects of high pressure on glass: A possible piezometer for the 100-kb region, Nature, 190, 798, 1961.

Wackerle, J., Shock-wave compression of quartz, J. Appl. Phys., 89, 922, 1962.

(Received January 7, 1971; revised March 22, 1971.) 